\title{
Assessment of a Cooperative-Creative Program of Assertive Behavior and Self-Concept
}

\author{
Maite Garaigordobil Landazabal \\ Paîs Vasco University
}

\begin{abstract}
This study examined the effects of a game program of assertive behavior, helpful behavior, and self-concept in children aged 8 to 10. A pretest-intervention-postlest design was used with a simple of 126 experimental and 28 control subjects. Three instruments were administered before and after intervention: the Children's Assertive Behavior Scale, Sensitivity Scale, and the Adjective Check List. Assertive behavior, helpful behavior, and self-concept were the dependent variables. Intervention consisted of a group play-session carried out once a week during the whole academic year. The program's games encourage children to cooperate and share, as well as to develop creative plity. The program included presentation, communication, help, cooperation, creativity, and emotional expression games. Results of multiple variance analyses suggest that the program caused significant improvement in assertive behavior $(p<.001)$ and self-concept $(p<.01)$. This paper reveals empirical evidence of the positive contribution of cooperative-creative play to child development. Key words: evaluation program, social behavior, self-concept, psycho-edicational interienton, child-play
\end{abstract}

\begin{abstract}
Este estudio evalúa los efectos de un programa lúdico de intervención psicológica en la conducta asertiva, en las conductas de ayuda y en el autoconcepto de niños de 8 a 10 años. Se utilizó un diseño pretest-intervención-postest con 154 participantes (grupo experimental, $n=126$; grupo control, $n=28$ ). Antes y después de la intervención se administraron tres instrumentos: ia Escala de Conducta Asertiva, la Escala de Sensibilidad Social, y el Listado de Adjetivos. Las variables dependientes fueron la conducta asertiva, la conducta de ayuda y el autoconcepto. La intervención consistió en la realización de una sesión de juego semanal durante un curso escolar. Los juegos del programa animan a tos niños a cooperar y a compartir, además de desarrollar su juego creativo. El programa incluye presentación, comunicación, ayuda-confianza, cooperación, creatividad grupal y juegos de expresión emocional. Los resultados de los análisis de varianza múltiple indican que el programa de juego estimuló significativamente una mejora del comportamiento asertivo $(0<.001)$ y del autoconcepto $(0<.01)$. El trabajo ofrece apoyo empirico sobre la contribución positiva del juego cooperativo-creativo al desarrollo infantil.

Palabras clave: evaluacion de programas, conducta social, autoconcepto, intervención psicoeducativa, juego intantil
\end{abstract}

This rescarch received the $1^{\text {st }}$ National Prize of Educational Research, 1994. from the Ministry of Education and Science. I thank Cristina De Paul for her collaboration and those who kindly volunteered to participate in this study.

Correspondence conceming this article should be addressed to Maite Garaigordobil, Facultad de Psicología. Untiversidad del Pais Vasco. Avenida de Tolosa, 70. 20009 San Sebastian (Spain). E-mail: ptpgalam@ss.ehu.es 
The purpose of this study was to evaluate the effects of a game program on social behavior and self-concept. Rescarch in this field is based on studies that have pointed out the positive effects of play on child development. During the last decades, numerous investigations from various theoreticalmethodological approaches have analyzed the relations between play and integral child development, concluding that play is a vital activity of great importance to human development (Bunker, 1991; Bruner, 1983; Eisert \& Lamorcy, 1996; Fisher, 1992; Gabbard, 1995; Garaigordobil, 1990. 1992a, 1992b, 1995a, 1995b, 1996, Garaigordobil \& Echebarria, 1995, Garaigordobil, Maganto, \& Etxeberria, 1996; Gonci, 1993; Gordon, 1993; Grineski, 1991; Levy, Wolfgang, \& Koorland, 1992; Patrick, 1996; Pellegrini, $[987$. 1988, 1989; Pellegrini \& Galda, 1993; Terr, 1990).

In general, the results of these observational and experimental studies suggest that child play (representative, cooperative, creative, etc.) is systematically related to personal and social development (Orlick, 1978a, 1978b. 1981; Vygotsky, 1933/1982). Several researchers conclude that play is an important instrument of communication and socialization, as in their games, children discover social life and rules reigning in adult relationships, they interactcooperate with their peers, and develop moral conscience by learning behavioral norms.

Moreover, playing promotes self-awareness - the development of personal conscience - because it provides children with the opportunity to explore their position in the world and get to know other people around them. In joyful interactions with their peers, chidren experience various situations in which feclings, attiludes, and relational behavior patterns with distinct nuances are involved. Joyful activities create a very broad and varied relational context in which children progressively gain awareness of themselves and knowledge of other people. Playing gives children the possibility to try out new relationship patterns and receive images of themselves, which facilitates their personal and social mauration process.

Studies that have analyzed the impact of systematic game programs on children's social behavior reveal positive results. However, researchers generally agree that when only supplementary opportunities for play are provided. these effects on social behavior do not appear. The results of investigations with a pretest-game program-postlest design suggest that playing stimulates: (a) positive effects and interactions among pecrs, and less aggressivencss and hyperactive behavior (Freyberg, 1973); (b) the development of social skills (Smilansky, 1968); and (c) an increase in pro-social behavior, as well as a decrease in the levels of overt aggression (Bay-Hinitz. Peterson, \& Quilitch, 1994; Garaigondobil, 1992a, 1992b, 1995a, 1996; Udwin, 1983).

This trend was also revealed in a recent reseatel (Garaigordobil, 1992a, 1992b) that experimentally assessed the effects of a game program applied weekly during onc academic year. The results of this study suggest that the program promoted: (a) a significant improvement in social behavior anong peers in the classroom context (increase in leadership behavior, social sensitivity, respect, and self-control, checrtulness, and decrease in aggressive behavior, anxietyshyness, and apathy-withdrawal); (b) higher development of group cooperation capacity; (c) a positive effect on socioaffective intragroup relations, by increasing mutual acceptance; and (d) an increase in indirect cognitive strategies of social interaction, as well as a decrease in aggressive cognitive strategies as a technique for conflict resolution.

Similar studies have also pointed out that competence for the role game, measured with a role dramatization technique. is directly related to social skills, its measured on a sociometric test (assessment by peers) and on a rating scale reported by the prolessor. It was confirmed that children who ate quite competcn at this game are also chosen more often by their classmates, obtaining high scores in the professor's evaluation of their social skilts in classroom (Hughes, Bootoo. \& Alcala, 1989).

Within the framework of the conclusions of the abovementioned studics, the purpose of the work presented herc is: (a) to design a psychological intervention program based on friendly, cooperative, and creative group-play; (b) to apply it weckly during one academic year; and (c) to evaluate its effects on assertive behavior, on helpful behavior towards excluded classmates. and on self-concept, that is, on personal and social development factors.

This study provides: (a) new empirical evidence of the importance of cooperative-creative play on child development; and (b) an experimentally validated tool of psychoeducational intervention. The new intervention program is related to another cooperative game program designed for children between 6 and 8 (Garaigordobil, 1992a. 1992b), and includes 60 different activities adapted to childen from 8 to 11 years of age, combining social behavior and creativity in an original way.

The hypotheses about the results of the present incrvention ate that it promotes: (a) an increase in assertive behavior toward other children in various social situations involving accepting compliments or criticism, expressing positive and negative feclings, saying "no," asking favors, responding to offers of help, initiating relationships, etc., by favoring a decrease in aggressive and passive behavior when interacting with peers; (b) an increase in helpful behavior towards classmates who are excluded from and rejected by the group; and (c) improvement in self-concept, especially regarding its social and affective-emotional dimensions.

\section{Method}

\section{Participants}

The sample consisted of 154 children from ages 8-10, distributed in 5 groups attending 3 rd and 4 th grade of 
Elementary Education, and registered at a school center in the province of Guipúzcoa, northern Spain. Out of the total mentioned, four groups were assigned to the experimental condition ( $n=126$ ), whereas one randomly chosen group was designated as control $(n=28)$.

\section{Materials}

The following evaluation instruments were administered before and after the intervention:

The Children's Assertive Behavior Scale (CABS; Wood, Michelson, \& Flynn 1978; Michelson \& Wood, 1982). This questionnaire evaluates children's social behavior by means of self-reports; it explores the passive, assertive, or aggressive responses of a child in different situations of interaction with other children. Items comprise siluations and behavioral responses, such as giving and receiving compliments, complaints, empathy, asking and refusing to initiate, maintain, or end conversations, asking favors, responding to insults, obtaining objects, expressing positive and negative feelings, etc. The scalc includes 27 items with 5 response-categories per item, varying along a continum of passive-assertiveaggressive responses, from which children choose the one that represents their habitual way of responding to a specific situation. The psychometric studies of this questionnaire showed high internal consistency (K-R $20=.78)$, reliability (test-retest $=86)$, and discriminant and convergent validity. No significant correlations were obtained between the CABS and sex, $r=-.16$, intelligence, $r=-.11$, or social desirability, $r=11$. Factor analyses revealed a homogeneous factor structure. The CABS showed discriminant validity and could accurately differentiate which children had received social skills training.

Sensitivity Scale. Socialization Battery (BAS; Silva \& Martorell, 1983). This scale assesses social behavior in the classroom and, more specifically, social sensitivity or help behavior in relation to classmates who are excluded or rejected by the members of the group. Items included in this scale explore a person's degree of consideration and concern for others, in particular, those members of the group having problems or being isolated. The evaluation of each child's behavior was carried out by the teacher of the group after an observation period. This evaluation was blind, as teachers were unaware of whether the children being rated belonged to the experimental or to the control group. The psychomettic studies of this questionnaire showed high internal consistency, $\alpha=.90$, reliability (test-retest $=.51$ ), and criterial validity, $r=.46$, oblained by means of a criterion variable (social adaptability) and criterial groups (adapted-inadapted).

The Adjective Check List (ACL; Gough \& Heilbrun, 1965). This test has been adapted to children in this age range with the purpose of evaluating self-concept. It contains a list of adjectives denoting positive quality, including descriptions of physical, intellectual, affective, and sociability reatures. Children must choose those adjectives from the list that describe them the best. The psychometric studies of this questionnaire showed high reliability (test-retest $=.86)$.

Questionnaire for the Assessnent of the Intervention Program (Garaigordobil, 1995a). This was incorporated in the postiest phase. Once the intervention, which lasted the entire academic year, had concluded, the children filled in a questionnaire designed ad hoc to evaluate the program. In this questionnaire, using a 4-point rating scale (not at all a lithle - quite a bit - a lot), they appraised the degree of enjoyment experienced, as well as the level of change they observed in themselves regarding various aims of the program such as; communicating, helping, sharing, cooperating, etc.

\section{Design and Procedure}

This study used a multi-group design with repeated pretest-postest measurements, with one control group. Four experimental groups were compared with the control group, including pre- and post-intervention measurements. The intervention program was the independent variable, whereas assertive behavior, self-concept, and helpful behavior were the dependent variables.

The research was conducted throughout one academic year and followed the procedure described hereafter. During the first weeks of the school course, a pretest assessment was performed using the above-mentioned instruments. In the second phase, the game program was implemented, consisting of one weekly game session lasting approximately 90 minutes and comprising 3 to 5 group games. A total of 20 game sessions were performed. The intervention took place on the same day of the week and at the same time of the day in a barrier-free classroom or in the gym. When the school year was over, in the post-intervention phase, the same instruments as in the pretest phase were administered, and a self-report was added, in which children gave their opinions on the changes observed in themselves regarding the target variables of the study. While the experimental groups were receiving the intervention, the control group received focused attention from a teacher, for a fixed, structured period of time, however, using academic activities that were not designed to promote personality changes.

The application of the game program was carried out by the regular teacher of each group, whereas the evaluation was performed by a collaborator who also acted as observer of the game sessions. A research group, consisting of 11 education professionals (psychologists, teachers, and pedagogues), was made up to conduct the research. The team was trained in systematic group seminars carried out during the same school year as the research, taking into account both the theoretical, conceptual approach underlying the program and the methodological aspects of the intervention. 


\section{Intervention}

This game program had two macro-goals. First, a preventive one, becaluse this experience is meant to prevent problems in social interaction and self-concept. Second, a development goal, because it is intended fundamentally to promote social development of each child in the group and to stimulate the development of a positive self-image.

The 60 games included in the program promote communication, cohesion, and confidence, as they are based on the idea of accepting, cooperating, and sharing. They all have five distinctive characteristics: (a) participation everybody takes part, nobody is left out or loses, and every playcr has a significant and necessary role in the game; (b) communication, because these activities promote positive intragroup communication by encouraging active listening habits; (c) cooperation - the structure of the game induces players to help each other so as to achicve at common group goal; (d) fiction - play is an imitation of real life, "lel's pretend we're... snakes, elephants, fruit, etc."; and (e) pleasure - the aim is for children to have fun while interacting in a constructive, positive way with their peers at school.

The games were arranged into six categories, according to the main social factor involved. The first category included presentation games, whose purpose was to promote improved acquaintance among the children during the first game sessions. An example of this kind of games is "Who is Who?" Players spread round the classroom, making themselves as comfortable as they wished. Each one received a piece of paper on which he or she had to describe his- or herself. After that, the pupils sat on the floor in a big circle, and the conductor of the game (teacher) placed the descriptions in a bag. The teacher then starled taking the messages out, one by one at random, and reading them aloud. When a player believed he or she had guessed the identily of at classmate, then the player raised his or her hand and, in at loud voice, identified the person being described at that moment. At this stage, the author of the description could say nothing. All messages were read successively.

In the second category, the program contained group communication-cohesion games, which were meant to encourage intragroup communication, friendly links, and verbalization of positive messages, thus improving the selfconcept of all the children in the group. An example of this kind of play is "Friendly Figures." In this game, participants were assigned to small teams of 4 to 5 children, who, assisting each other mutually, drew the figure of each one of them on a body-long sheet of paper delivered to each player. When all the figures were completed, children wrole their names on them. Once the teams had linished the drawings, the game conductor (teacher) asked each team, in turns, to place themselves facing the figures of another team. Thcy were then asked, in a communication process, to think of positive messages about their depicted classmates. When they had come up with positive messages for all their classmates, they wrote them on their respective figures. Later on, the players observed the ligures of all their classmates in the group, reading the messages that had been written on them.

The third category included help-confidence games, with the aim of increasing help-giving behavior among the children and encouraging confident feelings. An example of this kind of games is "Embraced." In this game, two players were designated as "pursuers," whercas the rest of the children ran about the classroom in all directions. After counting up to ten, the two pursucrs chased their companions, who were considered safe only when another person embraced them. When a player was touched by the pursuers, he/she became their assistint. One of the rules in this game was that players could not remain cmbraced for Iong and, thus, avoid the risk of being caught.

The fourth category of joyful aclivities incorporated in the program was denoninated group creativity games, because, apart from intragroup communication, these games stimulate creativity in its verbal, graphic, and dramatic aspects. An example of this kind of play is "The mysterious telegram." The game conductor (teacher) stated four key letters, for instance $\mathrm{P}$. C, $\mathrm{A}$, and $\mathrm{H}$. The players had to compose a telegram in such a way that each word in the text began with the corresponding key letter. For example. "Pay Close Attention Here." Each team of 3 to 4 players tried to make up messages for 10 minutes, and wrote them on a sheel of paper. Afterwards, the registered messages wcre exhibited in the big group. The instructions of this game were as follows:

A mysterious creature from another planet has sent us a telegram which is incomplete, as only the first letters of the four words composing it appear, the letters being ...(initial lctters are indicated here). Fach team must guess the possible message this mysterious being has sent us. The game consists in inventing 4-word messages in which each word begins with the letter in the corresponding order.

The firth category of games was group cooperation games, characierized by promoting help-giving relations amongst players, with the aim of achieving a common or group goal. An example of this kind of play is the "Cooperative blanket game." This game was played in teams of 8 to 10 players who formed a circle round a blanket. They gripped the edges of the blanket and a beach ball was placed at its cemer. During warming-up, the team threw the ball up in the air and then caught it again with the blanket, or made the ball roll along its edges. Afterwards, suggestions could be made for a team to throw the ball so another team could catch it and throw it back again, and so on. A team could throw the ball vertically and withdraw rapidly. so that another team could take its place and catch it with its blanket. This set of games included, on the one hand, body cooperition games and, on the other, cooperation games in activities involving various cognitive processes.

The last category of games included in the program was games for emotional expression, which promote expression of emotions through dramatization or combination of music 
and movement. For example, the game "Master Music," which is aimed at encouraging the expression of emotions with the body, using music as the stimulating element. The game consisted of dancing freely about the classroom, discovering and inventing the movements suggested by a piece of music, and imagining scenes related to it. Children danced freely for 5-10 minutes, moving about the classroom and dramatizing the situations suggested by the music.

The basic structure of a game session comprised three acts or phases, namely, opening, development of the game sequence, and closing phase. Upon the children's arrival in the barrier-free classroom, they were instructed to sit on the floor in a circle, and the opening phase of the session was begun, with a duration of 5-10 minutes. In the first session, the game conductor (teacher) explained the goals of the program to be accomplished throughout the course, he/she informed the pupils that they would play games once a week, and described their characteristics. The goals pursued by the play were briefly reminded in the remaining sessions at the opening phase (make friends, enjoy oneself, share, give and receive help so as to achieve group goals, create and invent in group, etc.).

While pupils remained in this circular position, the teacher explained the instructions or theme of the first game, thus initiating the development phase of the game sequence, which was supposed to last approximately 60 minutes. Once they had received instructions about the first game, the children organized themselves and carried out the instructions. When the game was over, the pupils returned to their circular position and received explanations and/or instructions about the second game. They then played the second game, repeating the same procedure with the 3 or 4 games that made up the session.

On completion of the session's activities, pupils sat in a circle again, allowing for the beginning of the closing phase, which lasted about 10-15 minutes. This phase was devoted to reflection and discussion about whatever events had occurred in the session. There were comments regarding the interactions involved, the quality of the products claborated by the pupils (drawings, handmade clay items, invented stories, etc.), the conflicts appearing during the activities and ways to resolve them, the degree of pleasure induced by the games, etc. In this stage, meta-cognitive elaboration of actions and interactions previously experienced was encouraged.

The outlined intervention was not a highly structured proposal with standardized sessions to be applied identically in any group. The program was semi-structured, providing 60 activities and a methodological procedure that permitted teachers to design the sessions according to the age and the specific characteristics of the group. The teachers and their assistants systematically designed the session, taking into account the structural characteristics of the group itself, as well as the events which had taken place in previous sessions, each one of which was analyzed upon completion.
There were two stages when planning a session. In the first place, selection of three or four joyful activities to be performed and, it the second place, organization of the game sequence. In order to select appropriate activities, a structural analysis of each game was carried out, which involved answering two questions: (a) what psycho-motor, intellectual, affective, and social aspects of child development does the game mobilize? and (b) what is its level of difficulty? The activities selected were analyzed according to these two parameters and, thereafter, the game sequence was organized following a set of suggestions such as: (a) begin the sessions with a game for the entire class; (b) combine various classes of relational games (couples, small teams, entire class); (c) combine activitics that mobilize different processes (communication, help, cooperation, etc.).

The design of the sessions did not only follow the abovementioned 2-stage procedure (game selection and analysis, and sequence organization), but also took into account the observer's data registry of what had happened in the group in previous sessions. In every classroom there was an observer whose task was to describe events occurring in the game sessions during the proposed activities, using a narrative record tcchnique. The observer built up a "Session Diary" by registering information related to the degree of pleasure, group interactions, atmosphere in the group, degree of respect for game rules, or creativity of the game products elaborated. These data were used to analyze the group, regarding the target variables of the intervention, and to perform the systematic assessment of each game session. The results of this assessment conditioned the planning of the following sessions. This systematic assessment was carried out with an evaluation questionnaire designed ad hoc. The questionnaire used an assessment scale ranging from 0 to 10 in order to provide estimates of various indexes such as: (a) degree of pleasure, (b) Ievel of participation, (c) atmospherc in the group: organized, cheerful, peaceful, (d) interactions: friendly, flexible association, help and cooperation behavior, communication and level of listening, (e) respect for game rules, and (f) creativity of the products elaborated: fluency, flexibility, originality, fantasy, etc.

\section{Results}

To analyze the changes caused by the game program, multiple variance analyses (MANOVA) were performed on the raw scores obtained on the six variables measured before and after the intervention. Analyses were carried out using the SPSS Windows 7.5 package.

Changes in self-concept. In order to assess changes in children's self-concept, raw scores obtained on the list of adjectives were used as input for a MANOVA. In the fitst place, we analyzed the equivalence of experimental and control groups in the pretcst phase regarding the three self-concept variables tested. The results showed no statistically significant 
Table 1

Pretest, Posttest Means and Standard Deviations for both Experimental and Control Groups in Self-Concept

\begin{tabular}{lcccccccc}
\hline & \multicolumn{3}{c}{$\begin{array}{c}\text { Experimental Group } \\
(n=126)\end{array}$} & & & \multicolumn{2}{c}{$\begin{array}{c}\text { Control Group } \\
(n=28)\end{array}$} \\
& & Pretest & & & Postlest & Pretest & Posttest \\
\hline Variables & $M$ & $S D$ & $M$ & $S D$ & $M$ & $S D$ & $M$ & $S D$ \\
\hline Affective Self-concept & 6.5 & 2.7 & 7.9 & 2.1 & 6.7 & 2.1 & 7.1 & 2.2 \\
Social Self-concept & 4.6 & 2.3 & 6.9 & 1.1 & 4.8 & 2.1 & 5.2 & 2.0 \\
Global Self-concept & 16.8 & 6.2 & 21.4 & 3.8 & 17.0 & 4.3 & 18.3 & 5.2 \\
\hline
\end{tabular}

a priori differences between the groups (Multivariate Pillais $F=0.300, p=825$ ). In the second place, a MANOVA was carried out to compare posttest-pretest differences between experimental and control groups (improvement), yielding statistically significant differences (Multivariate Pillais $F=$ $4.828, p=.003$ ). The results obtained for the self-concept variable (affective and social characteristics, global self-concept) are presented in Table 1.

The results of ANOVA (see Table 1) revealed that, in the pretest phase, there were no statistically significant differences between experimental and control subjects in self-concept regarding affective characteristics, $F(1,152)$ $=0.061, p=.804$, and regarding sociability features, $F(1$, $152)=0.148, p=.700$, and in global self-concept, $F(1$, 152) $=0.006, p=.934$. However, posttest-pretest differences between experimental and control groups were statistically significant in self-concept regarding affective characteristics, $F(1,152)=4.309, p=.040$, in self-concept regarding sociability features, $F(1,152)=15.950, p=.000$, as well as in global self-concept, $F(1,152)=9.417, p=$ .003 . These data suggest a statistically significant impact of the program on self-concept. In agreement with our hypotheses, the intervention stimulated an increase in global self-concept, especially in relation to affective and sociability aspects, more closely linked to the characteristics of this intervention.

Changes in social behavior: In order to evaluate the effect of the game program on assertive behavior in different social situations with other children, a MANOVA was performed on the scores obtained on the assertive behavior scale (CABS), which measured aggressive and passive responses in various social interaction situations. The effect of the intervention on helpful behavior directed towards excluded companions was also analyzed, using the Socialization Battery. First, a MANOVA was performed to assess the equivalence of experimental and control groups in the pretest phase concerning the three tested social behavior variables. Results showed statistically significant a priori differences between the two groups (Multivariate Pillais $F=8.653, p=$ .000 ). Second, a MANOVA was carried out to compare posttest-pretest differences between experimental and control subjects, revealing statistically significant postest-pretest differences between the two group conditions (Multivariate Pillais $F=12.216, p=.000$ ). The results of the ANOVA for these three variables are presented in Table 2 .

The results of the ANOVA (see Table 2) suggested that there were no statistically significant differences in the pretest phase between the experimental and control subjects as concerns passive behavior, $F(\mathrm{l}, 152)=0.839, p=.361$. However, differences were revealed with regard to aggressive behavior, $F(1,152)=6.245, p=.014$, as experimental subjects obtained higher scores on this variable. Posttestpretest differences between the experimental and control groups were statistically significant for aggressive behavior, $F(1,152)=8.115, p=.005$, and passive behavior, $F(1,152)$ $=11.054, p=.001$. These results indicated that the experimental subjects experienced a significant decrease in passive behavior in various situations of interaction with

Table 2

Pretest, Posttest Means and Standard Deviations for both Experimental and Control Groups in Assertive Behavior

\begin{tabular}{|c|c|c|c|c|c|c|c|c|}
\hline \multirow[b]{3}{*}{ Variables } & \multicolumn{4}{|c|}{$\begin{array}{l}\text { Experimental Group } \\
\qquad(n=126)\end{array}$} & \multicolumn{4}{|c|}{$\begin{array}{c}\text { Control Group } \\
\qquad(n=28)\end{array}$} \\
\hline & \multicolumn{2}{|c|}{ Pretest } & \multicolumn{2}{|c|}{ Posttest } & \multicolumn{2}{|c|}{ Pretest } & \multicolumn{2}{|c|}{ Posttest } \\
\hline & $M$ & $S D$ & $M$ & $S D$ & $M$ & $S D$ & $M$ & $S D$ \\
\hline Aggressive behavior & 11.2 & 8.9 & 4.1 & 3.8 & 6.7 & 4.9 & 4.0 & 3.5 \\
\hline Passive behavior & 7.7 & 4.7 & 6.9 & 3.4 & 6.8 & 3.9 & 9.2 & 4.5 \\
\hline Helpful behavior & 15.4 & 4.5 & 18.1 & 4.5 & 20.2 & 4.5 & 20.4 & 5.1 \\
\hline
\end{tabular}


other children. Although experimental subjects presented a greater decrease in aggressive behavior, they also obtained higher scores in the pretest phase. This fact conditioned our work with the ANOVA, compelling us to use the initial scores as covariant of the analysis. The covariance analysis (ANCOVA) did not confirm a statistically significant effect of the program, $F(l, 152)=2.24, p=.136$. Nevertheless, the results suggested a positive effect of the program on assertive behavior, as it enhanced social interaction, regarding situations that involve accepting compliments or criticism, expressing positive and negative feelings, saying "no," requesting favors, responding 10 offers of help, or initiating relationships, etc.

Concerning helpful behavior directed at excluded companions rejected by the group, the ANOVA (see Table 2) showed evidence that posttest-pretest differences between experimental and control subjects were statistically significant, $F(1,152)=9.636, p=.002$. However, there were also statistically significant differences botween them in the pretest phase, $F(1,152)=24.262, p=.000$, as experimental subjects obtained lower scores than did control subjects; that is, these groups were not very homogeneous a priori. This fact also conditioned our work with the ANOVA, leading to the compulsory use of initial scores as covariant of the analysis. The ANCOVA performed did not confirm a statistically significant effect of the program, $F(1,152)=1.59, p=.208$. Thus, and despite observing a greater increase in helpful behavior in experimental subjects and no changes in control ones, we could not confirm a statistically significant impact of the program.

The results of these ANOVAs show a similar trend as the data obtained with a subjective evaluation questionnaire of the program, which was administered to the children upon completion of the intervention. In this questionnaire, pupils informed about the degree of change (not at all - a little quite a bit - a lot) they observed in themselves, in relation to the different goals of the program. The analyses of frequencies and response percentages revealed that: (a) 68,3 $\%$ of the sample $(n=86)$ emphasized a major improvement in self-concept, (quite a bir or a lor); (b) 63,5\% ( $n=80)$ admitted a high increase in their communication level with their peers; (c) 69,8\% $(n=88)$ observed that they expressed their feelings "quite a bit" or "much more" in different relational situations with their companions; and (d) $59.5 \%$ ( $n=75$ ) said that during this period they had established new friendships with their classmates.

We could not clarify the effect of the program because of statistically significant differences between experimental and control subjects in the pretest phase concerning the variable "helpful behavior" directed at excluded companions in the group. Although experimental subjects experienced a greater increase in this aspect, they also presented a more unfavorable starting-point. Nevertheless, children who participated in the game program informed of an important increase in their helpful behavior in gencral, because: (a)
$80,9 \%$ of the sample $(n=102)$ observed a great increase in their cooperation bchavior involving reciprocal help processes; and (b) $71,4 \%(n=90)$ informed that, after completion of the game program, they engaged in "quite a bit" or "much more" relations concerning helping and sharing behavior with their peers in classroom.

\section{Discussion}

The results of the ANOVA performed suggest that this group game program enhanced: (a) improvement in global sclf-concept, especially in relation to affective and sociability characteristics; and (b) significant decrease in passive behavior, implying an improvement in assertive behavior in interactions with other companions in social situations.

The positive effects of the program on various variables tested derive, on the one hand, from the characteristics of the games themselves, and, on the other hand, from the emphasis placed on the closing phase of the game sessions, in which the children rellect upon the satisfaction generated when receiving positive messages from onesclf, the cmotional damage from perceiving negative messages or being rejected by others, the benefits as an outcome of cooperation versus competition, or the difficulties presented when working in groups.

The results obtained on evaluating this program are consistent with various investigations concerning children's play (Bay-Hinitz et al., 1994; Eisert \& Lamorey, 1996; Fisher, 1992; Garaigordobil, 1992a, 1992b, 1995a, 1995b; Garaigordobil \& Echebarria, 1995; Garaigordobil et al.. 1996; Gordon, 1993; Göncui, 1993; Grineski, 1991; Orlick 1978a, 1978b, 1981; Vygotsky, 1933/1982). This research, following the trend of similar studies, points out that a friendly, non-competitive game program promoling creativity in the context of cooperative interactions, can provide important benefits for a child's personal and social development. Overall, the conclusions of this study suggest the importance of including structured experiences directed at encouraging capacity for group cooperation and creation in the academic curriculum.

One of the limitations of this study is related to the size of the control group. The number of children in this group is small compared to the number of children in the experimental condition. The random selection of this small number of children could influence the results. Moreover, another suggestion concerning the assessment instruments could be the use of other instruments that assess cognitive and personality functioning and that do not involve self-report. For example, projective techniques, such as the test of children's human figure drawings (Koppitz. 1968) or cognitive tests that measure how emotions and information are coordinated. Also, there may be other benefits of the program that are not revealed because the assessment instruments fail to detect them. 


\section{References}

Bay-Hinitz, A.K., Peterson. R.F., \& Quilitch. H.R. ([994). Cooperative games: A way to modify aggressive and cooperalive behaviors in young ctildren. Joumal of Applied Behavior Analysis, 27, 435-446.

Bruner, J. (1983). Platy, thought, and language. Peabody Jourmal of Education. 60, 60-69.

Bunker. L.K. (1991). The fole of play and motor skill development in building children's self-confidence and self-esteem. Elementary School Journal, 91, 467-471.

Eisert. D.. \& Lamorey, S. (1996). Play as a window on child development: The relationships between play and other developmental domains. Early Education and Developmen, 7 . $221-234$

Fisher, E.P. (1992). The impact of play on development: A ntetaanalysis. Play and Culture, 5, 159-181.

Freyberg, I.T. (1973). Increasing the imaginative play of urban disadvantaged kindergarten children through systematic training. In J.L. Singer (Ed.). The child's world of make-believe (pp. 129-154). New York: Academic Press.

Gabbard, C. (1995). P.E. for preschoolers: The right way. Princinal, 74. $21-22$.

Garajgordobil, M. (1990). Juego y desarmllo infantil. Madrid: Seco-Olea.

Garaigordobil, M. (1992a). Diseño y eqaluación de un programa lúdico de intervención psicoeductive con niños de $6-7$ años. (Ph.D. University Microfilms No. B-12346/94). País Vasco University, Spain.

Garaigordobil, M. (1992b). Juego cooperativo y socializacion en el aula. Madrid: Seco-Olea.

Garaigordobil, M. (1995a). Psicologia para el desarrollo de la cooperación y la creatividad. Bilbao: Descice de Brouwer.

Garaigordobil, M. (1995b). Intervención en la creatividad: evaluación de una experiencia. Revista lberomericana de Diagnóstico y Evaluación Psicologica, 1, 37-62.

Garaigordobil, M. (1996). Evaluación de ma intervención psicoeducativa en sus efectos sobre la conducte prosocial y la creatividad en niños de 8 a $/ 1$ años. Madrid: Ministerio de Educación y Cultura.

Garaigordobil. M., \& Echebarria, A. (1995). Assessment of a peer helping game program on children's development. Jonrmal of Research in Childhood Education, 10, 63-69.

Garaigordobil, M. Maganto, M., \& Etxeberria. J. (1996). Effects of a cooperative game program on socio-affective relationships and group cooperation eapacity. European Jounal of Psychological Assexwent, 12, 140-151.

Göncü, A. (1993). Development of intersubjectivity in social pretend play. Human Development, 36, 185-198.

Gordon, D.F. (1993). The inhibition of pretend play and its implications for development. Haman Development. 36. 215 234.

Gough, H.G., \& Heilbrun. A.B. (1965). The Adjective Che's List manual. ACL. Palo Alto, CA: Consulting Psychologist Press.
Grineski, S.C. (1991). Effects of cooperative games on the prosocial behavior interactions of young children with and without impairments. Dissertation Abstracts International, 5/(8-A), 2629 .

Hughes. J.N., Boodoo, G. \& Alcala, J. (1989). Validation of roleplay measure of children's social skill. Jommal of Abnormal Child Psychologb: 17, 633-646.

Koppitz, E. (1968). Prychological evaluation of children's Human Figure Drawings. New York: Grune \& Stratton.

Levy, A., Wolfgang, CH., \& Koorland. M. (1992). Sociodramatic play as a method for enhancing the language performance of kindergarten age students. Early Childhord Research Quarterly: 7. 245-262.

Michelson, L.. \& Wood, R. (1982). Development and psychometric properties of the Children's Assertive Behavior Scale CABS. Joumal of Behaviorul Assessment, 4, 3-14.

Orlick, T. (1978a). The cooperative sports and games book. New York: Pintheon Books.

Orlick, T. (1978b). Winning through cooperation: Competitive imsanty - cooperative altenatives. Washington, D.C.: Acropolis.

Orlick, T. (1981). Positive socialization via cooperative games. Delolopmontal Pspchology, 17, 426-429.

Patrick. T. (1996). Play: An impontant component of preventive behavior management. Paper presented at the Annual Conference of the Southern Early Childhood Association ( $p$. 26). Little Rock, AR.

Peltegrini, A.D. (1987). Rough and tumble play: Developmental and educational significance. Educational Psychologist, 22, $23-43$.

Pellegrini, A.D. (1988). Elementary school children's rough and tumble play and social competence. Developmental Psychologry, 24. $802-806$

Pellcgrini. A.D. (1989). Elementary school children's rough-andtumble platy. Eurly Childhood Research Qwarterly, 4, 245-260).

Pelhegrini. A.D. \& Galda, L. (1993). Ten years after; A recxamination of symbolic play and literacy research. Realing Research Quarterly, 28, 163-175.

Silva, F., \& Mantorcl], C. (1983). Bateria de socializacion. Madrid: TEA.

Smilansky, S. (1968). The effect of sociodramatic play on disad'mataged prewhool children. New York: Wiley.

Terr. L. (1990). Tor wared to cry New York: Harper \& Row.

Udwin, O. (1983). Imaginative play training as an intervention method with insticutionalised preschool children. British Joumal of Educational Psychology, 53, 32-39.

Vygotsky, L. S. (1982). El juego y su función en el desartolto psíquico del nirio. Cuaternos de Pedagogía. 85, 39-49.

Wood, R., Michelson, L., \& Flynn, J. (1978). Assessment of assertive behavior in elementary school children. Paper presented at the Annual Meeting of the Association for Advancement of Behavior Therapy. Chicago, IL.

Received September 10, 1998 Revision received November 1, 1998 Accepted March 10, 1999 